Cuestiones de filosofía

ISSN: 0123-5095

Vol. 1 - No. 17

Año 2015

pp. $15-37$

\title{
DE LA METAFÍSICA DE LA MÚSICA A LA MÚSICA EN TIEMPOS POSMETAFÍSICOS O LA MÚSICA Y EL NIHILISMO
}

\author{
From the metaphysics of music to music in the \\ ostmetaphysics times Or the music and nihilism*
}

Manuel Oswaldo Ávila-Vásquez

manuelavilavasquez@gmail.com

Universidad Pedagógica y Tecnológica de Colombia (Colombia)

Fecha de recepción: 14/01/2015

Fecha de evaluación: 14/02/2015

Fecha de aprobación: 1/09/2015

\section{Resumen}

Estas consideraciones buscan reflexionar, a partir de dos versiones de La cabalgata de las valkirias, de $\mathrm{R}$. Wagner, y de la banda sonora de una reconocida película norteamericana, acerca de cómo se manifiesta el poder de nuestra propia época. Lo anterior, teniendo como referente uno de los encuentros más significativos de la historia de la música y de la filosofía: el de Richard Wagner y Friedrich Nietzsche en casa de Bockhaus (cuñado del primero), en 1868; en este, teniendo como telón de fondo la figura de Schopenhauer, se dio alumbramiento a lo que el joven Nietzsche denominó, en El nacimiento de la tragedia, "la tarea más suprema y la actividad propiamente metafísica de la vida" (1984b, 39). Pero, ¿qué significan estas palabras en boca del joven Nietzsche?, ¿acaso son simplemente la caracterización de la música grandilocuente del músico de Leipzig? o, por el contrario, ¿son la

* Este documento se inscribe en la línea de investigación dinámicas culturales y relaciones de poder del Grupo de Investigación Filosofía, Sociedad y Educación, de la Universidad Pedagógica y Tecnológica de Colombia. 
manifestación más fidedigna de la firme convicción de que la música se constituye en la actividad propiamente metafísica del ser humano?, y, hoy en día, en una época que bien podríamos denominar posmetafísica, ¿qué pasa con la música? El presente ensayo pretende, entonces, especular, a partir de estas preguntas, en torno no solo del carácter metafísico de la música en tiempos de Wagner y Nietzsche, sino meditar a propósito del sentido mismo de la música en una época estridente como la nuestra.

Palabras clave: Wagner, Nihilismo, Voluntad.

\begin{abstract}
These considerations seek to reflect, from two versions of The Ride of the Valkyries by Wagner and the soundtrack of a renowned American film, about the way that power of our own time manifests. This taking as reference one of the most important meetings in the history of Music and Philosophy: the match between Richard Wagner and Friedrich Nietzsche in Bockhaus home (brother of the first) in 1868. That meeting in which, with the backdrop of the huge figure of Arthur Schopenhauer, gave birth to what the young man named Friedrich Nietzsche in The Birth of Tragedy, "the highest task and proper metaphysical activity of life" (1984b , 39 ). But what do these words mean in the mouth of the young Nietzsche? Did they simply are characterizing the bombastic music of Leipzig 's famous musician? Or, on the contrary, are such words the most reliable manifestation of the strong belief that music is properly the metaphysical activity of man? And today, at a time when what might be called postmetaphysical, what about the music? This essay, as stated, intended to speculate from these questions about not only the metaphysical character of music in times of Wagner and Nietzsche, but to meditate on the purpose the very meaning of music at a noisy time as ours.
\end{abstract}

Keywords: Wagner, Nihilism, Will. 
...durante toda su vida repetía esta frase: que su música no significa solamente música, sino que significaba más...

"No solamente música", así no habla ningún músico.

Nietzsche, El caso Wagner

\section{INTRODUCCIÓN}

Para quien escucha La cabalgata de las Valkirias, de Richard Wagner, no es posible dejar de sentir cierto tipo de estremecimiento; pero, ¿qué hay en esta elocuente música que nos lleva a tal estado de ánimo?, ¿será acaso el hecho indiscutible de que en esta música se hace manifiesto el estruendo de los frenéticos corceles de las míticas furias del antiguo pueblo germano, es decir, de las temibles portadoras de la muerte?, ¿habrá allí algo más que una simple representación musical de un antiguo mito?, ¿qué es lo que verdaderamente resuena en esta música?; a esto es a lo que quiero responder. Para ello dividiré este texto en tres partes: las dos primeras dedicadas a la popular composición de Richard Wagner (a la que el compositor debe su fama), con el fin de, a partir de allí, meditar acerca de nuestro tiempo; en la tercera parte echo mano de la banda sonora de una conocida película norteamericana, Terminator, con el objetivo de analizar si el espíritu que anima esta composición es el mismo que anima La cabalgata de las Valkirias wagneriana: el espíritu del nihilismo.

Considero dos versiones de La cabalgata de las valkirias; la primera es una reconocida puesta en escena de esta obra en términos que bien podríamos denominar clásicos; la segunda se encuentra en el marco de la película Apocalypse Now, del director Francis Ford Coppola, del año 1979. Veamos de qué trata todo esto.

\section{De la metafísica de la música ${ }^{2}$}

La noche encontró a Nietzsche lleno de inquietud aquel 8 de noviembre de 1868 , no solo por el recuerdo del altercado con el mensajero del sastre, del cual hace saber a su amigo Erwin Rodhe en una carta del 9 de noviembre de ese mismo año,

2 Para aproximarse a la versión clásica de La cabalgata de las valkirias, de Wagner, se puede recurrir a la siguiente dirección electrónica: http://www.youtube.com/ watch?v=1aKAH_t0aXAL 
sino porque, justo ese día, conocería, en casa del profesor Bockhaus, de la ciudad de Leipzig, a uno de los hombres más eminentes y controvertidos de su tiempo: el compositor Richard Wagner (1813-1883). Por aquel entonces, el famoso autor del Anillo de nibelungo contaba unos 56 años de edad, 31 años más que el joven estudiante de filología clásica que estaba a punto de tratarlo, por primera vez, luego de algunos intentos fallidos.

Cuando por fin Nietzsche consiguió estar frente a frente con el famoso compositor pudo constatar en el rostro de este las huellas de una existencia esculpida con los ideales del pangermanismo, y la esforzada apuesta por eso que el artista llamaba la música del futuro. Al decir del biógrafo de Nietzsche, Curt Paul Janz, al hablar precisamente de la figura de Wagner, advirtió los profundos vestigios de "una existencia dramática, llena de grandes momentos, pero sobre todo de humillaciones" (1981, p. 21); en otras palabras, pudo ver hecha carne una vida tallada por el ideal de la obra de arte total (Gemamtkunstwerk), esto es, de esa "unión mística de los individuos en un pueblo [que] tiene su correlato en la unión mística de todas la artes" (Fubini, 2007, p. 29), y cuyas consecuencias trágicas, algo que pudo intuir años más tarde Nietzsche, no solo se harían visibles, como resulta obvio, en el adusto rostro del eminente maestro o en el enfermizo espíritu del desdichado Ludwig II de Baviera, sino en la apropiación que hicieron de esta categoría los nacional-socialistas en la década de 1930.

Nada extraño de la obra de un individuo que, como indica el citado Curt Paul Janz, "era uno de los hombres respetados y a la vez más odiados de su tiempo, creador de una obra tan importante como revolucionaria, y por eso discutida; una personalidad demoniaca, mágica, no sin un recubrimiento protector de charlatanería" (1981, p. 21). Quizá debido justamente a todo esto, la personalidad arrolladora de Richard Wagner produjo un entusiasmo tal en el joven estudiante de filología clásica Friedrich Nietzsche, que este no pudo menos que tener la impresión, en aquel instante, de encontrarse frente a la encarnación viviente del genio, tal como lo había concebido su maestro Arthur Schopenhauer. Pero, ¿qué era lo que resonaba en la música de este hombre "síntesis de inhumanidad y superhombre..." (Nietzsche, 1984, p. 61) que hechizaba de manera tan poderosa al futuro autor del Zaratustra, y que en otros, por el contrario, generaba una repulsión infinita? Echemos un vistazo al espíritu de este hombre y de su música.

Wagner nació en la ciudad sajona de Leipzig, el 22 de mayo de 1813, justo dos años antes de que se instaurara en toda Europa uno de los periodos más retardatarios 
de su historia: la Era Metternich. En 1815, tras la derrota de Napoleón I en Waterloo, Alemania, aunque no tan fraccionada como en tiempos de la confederación del Rin, estaba convertida en una verdadera colcha de retazos de la cual hacían parte unos 39 Estados independientes, que estaban reunidos en la llamada Confederación Alemana, en la que el Imperio Austriaco y el reino de Prusia llevaban la voz cantante. Como se sabe, la Era Metternich llevó, a la postre, a levantamientos en toda Europa, en 1830 y 1849, en los que también participó Richard Wagner. Estos sucesos, propios de la vida europea en pleno auge de la revolución industrial y del espíritu romántico, irían a desempeñar un papel decisivo en la existencia del autor de Tannhäuser, que, por aquel entonces, se hallaba cerca de hombres como Laube (en tiempos de la Revolución de Julio), Mijail Bakunin, el editor radical August Röckel, y de la lectura de autores como Pierre Proudhon (en la década de 1840) y, pocos años después, de Ludwig Feuerbach y de los teóricos de la socialdemocracia.

¿Qué tiene que ver, empero, todo esto con lo que resuena en La cabalgata de la valkirias?; la respuesta parece evidente; teniendo en cuenta lo dicho, habría que decir simplemente que en la famosa composición wagneriana se harían patentes las convulsiones de la época en la que vivió el compositor. Una época de agitación social en la que muchos, frente al estado de alienación en el que vive el ser humano, añoran su redención. Es en este sentido que puede reconocer Fubini, en su ya referido libro El romanticismo: entre música y filosofía: "Buena parte del pensamiento estético musical desde la mitad del siglo XVIII hasta la crisis del romanticismo -o sea, durante más de un siglo- aparece recorrido, como un hilo rojo, por el concepto de alienación del hombre a causa de la civilización y de su redención o aspiración a la redención por medio de la música" (2007, p. 21). De este modo, en La cabalgata de las Valkirias resonaría el ocaso y la redención de una $\mathrm{Era}^{3}$. Sin embargo, cuando se escucha con más detenimiento esta composición,

3 Sobre la relación de Richard Wagner con su época resultan altamente significativas estas palabras de Eduardo Pérez Maseda al inicio de su libro Música como idea, Música como destino: Wagner-Nietzsche: "Ante una figura como la de Wagner, depositaria de una iluminada capacidad de síntesis, siempre receptor de todo cuanto lo rodea sea o no musical, no nos hemos de extrañar de que Thomas Mann (...) vea a Wagner definiendo las características esenciales de la segunda mitad del siglo XIX y, por supuesto, no sólo desde la vertiente intrínsecamente musical ni tampoco desde una perspectiva de "las artes", sino desde la óptica de una absorción en la propia obra wagneriana de todas las inquietudes de su tiempo, desde la novela (un caso similar encentra Mann en Zola) hasta la política. / Igualmente, no tiene nada de extraño que Spengler, en su macropensamiento de grandes ciclos, Wagner sea el final decisivo de lamúsica europea y el punto en que se resumen los fenómenos más significativos de su tiempo" (1993, p. 36). 
parece guardar algo mucho más profundo. No resulta nada extraño por eso que el sentido insondable de su propia música no lo haya encontrado Wagner en el diagnóstico, respecto a su tiempo, de los anarquistas y de los socialistas, a los que era efecto en la década de 1840, como se ha indicado, ni, mucho menos, en las barricadas de Dresde, sino en la lectura, en 1854, de El mundo como voluntady representación, de Arthur Schopenhauer ${ }^{4}$.

Empero, ¿qué era lo que había en este sorprendente libro que hacía que Wagner se sintiera como en casa?, mejor aún, ¿no era este libro, acaso, tan solo la síntesis más lograda de eso que, de tiempo atrás, venía resonando en su obra y que había logrado, justo en 1854, una intensidad nunca antes vista, en su soberbia cabalgara de las Valkirias?; mas ¿qué era ese algo que irrumpía allí con tanta fuerza y que era capaz de desbordar su propio tiempo? Para responder adecuadamente a estas preguntas se torna necesario escuchar, ahora, la voz de Schopenhauer, pues solo de esta manera nos será dado atisbar en el abismante corazón de la obra del egregio músico de Leipzig.

No resulta difícil imaginar la emoción que sentía Richard Wagner al leer, en su gabinete de trabajo aquel año, El mundo como voluntad y representación, especialmente el parágrafo 52. No era para menos, allí encontró el músico eso que Arthur Schopenhauer denominaba sin más metafísica de la música, y ¿cómo no iba a emocionarle esto? Ningún filósofo, antes de célebre pesimista, se había atrevido a hacer algo semejante; es más, como se sabe, desde los tiempos de Platón los filósofos siempre habían mantenido una relación problemática con la música, y, esto lo sabía muy bien Richard Wagner. Dicho sea entre paréntesis, fue precisamente este entusiasmo de Wagner hacia el famoso filósofo de Danzig lo que tanto impresionó al joven F. Nietzsche de aquella primera conversación sostenida con el gran maestro en casa de Bockhaus. No resulta por eso sorprendente que en la misiva escrita a Rodhe, a la que se ha atendido unas líneas más arriba, afirme: "mantuve con él una conversación sobre Schopenhauer, y ya puedes comprender qué placer fue para mí oírle hablar de él con calor indescriptible, contándome lo que le debe y que es el único filósofo que ha conocido la esencia de la música" (1989, p. 119). Dejemos por el momento el encuentro de Nietzsche con el gran maestro, y volvamos al gabinete de trabajo de Wagner en 1854.

4 Vale la pena recordar que este fue el mismo año en el que el compositor terminó el famoso preludio al acto tercero a la segunda de las óperas (La valkiria) de El anillo del nibelungo, lo que hoy se conoce como La cabalgata de las Valkirias. 
Sí, Wagner lo sabía; antes de Arthur Schopenhauer ningún filósofo se había atrevido a dar su verdadero lugar a la música, y esto lo maravillaba; pero ¿qué era eso tan importante que el músico adeudaba al filósofo y que Wagner, años más tarde, le confió aquella noche de 1868 al joven Nietzsche?; ¿acaso el tema mismo de $L a$ cabalgata de la Valkirias? Mejor aún, ¿cuál era esa esencia de la música a la que se refería el compositor y que, según él, hizo patente de modo tan elocuente el autor de El mundo como voluntad y representación? La respuesta a estas preguntas, como se ha señalado, las encontró Wagner en la lectura del parágrafo 52 del libro III de la genial obra del "último gran alemán que merece ser tenido en cuenta" (1984a, p. 99), tal como se refiere Nietzsche a su maestro Schopenhauer en $E l$ crepúsculo de los ídolos, de 1888.

No hay que ponerlo en cuestión, la lectura de El mundo como voluntad y representación había arrojado a Wagner en una especie de éxtasis; nada insólito, si se tiene en cuenta que Arthur Schopenhauer hace notar allí cómo -tras haberse referido al arte arquitectónico, que, a su entender, no es otra cosa más que: "la objetivación de la voluntad en su grado inferior de su visibilidad" (2009, p. 311), y, por otra parte, haber concluido el parágrafo 51 con una interesante consideración a propósito de la tragedia; en breves palabras, acerca del "grado superior de objetivación de la voluntad, [la cual] nos pone ante la vista con terrible magnitud y claridad aquel conflicto suyo consigo misma" (2009, p. 311)-, la música, que es, nos dice este escritor, "un arte grande y magnifico, [que] actúa tan poderosamente en lo íntimo del hombre" (2009, p. 311), se revela ahora como el único medio capaz de lanzarnos plenamente a un estado de arrobamiento semejante a aquel que sentía el gran músico en aquel momento, leyendo a Schopenhauer ${ }^{5}$.

5 Sobre este punto vale la pena transcribir aquí lo dicho a este respecto por Rüdiger Safranski en su libro Nietzsche. Biografía de su pensamiento: "lo cierto es que el sentimiento de arrobo es más fuerte todavía en la propia improvisación al piano, a la que podía entregarse [Safranski se refiere desde luego a Nietzsche] durante horas, olvidado de sí y del mundo. Paul Deussen, el amigo de juventud, relata una escena conocida y tristemente famosa, que tiene que ver con ese arrobamiento: / "Nietzsche había partido solo hacia Colonia un día de febrero de 1865, y allí se agenció de un mozo de servicio que lo guiara a través de las cosas dignas de ver. Al final le rogó que lo llevara a un restaurante. Pero el acompañante lo llevó a una casa de mala reputación. Nietzsche me contaba al día siguiente: 'De pronto me vi rodeado por media docena de apariciones en lentejuelas y gasa, con mirada expectante puesta en mí. Durante un tiempo me quedé sin palabras. Pero luego me dirigí hacia un piano, que era el único ser con alma en aquel grupo, y toqué algunos acordes, que mitigaron mi rigidez y salí a la calle"'”' (2010, p. 19). 
Pero, ¿por qué justamente la música es capaz de arrojarnos a tal estado de arrobamiento?, ¿acaso es algo más que un simple divertimento? Para Schopenhauer la respuesta es clara. Aunque resulta evidente que la música, como las demás artes, establece una relación mimética con el mundo, cuando nos lanza a este estado de arrobamiento nos hace, al mismo tiempo, atisbar en el corazón mismo de las tinieblas ${ }^{6}$. De ahí que este filósofo le atribuya "un significado mucho más serio y profundo, referente a la esencia íntima del mundo y de nuestro yo" (2009, p. 312). ¿Qué significan estas palabras? Para el connotado autor de El Mundo como voluntady representación resulta evidente: la música, "en cuanto representación”, "establece una relación (...) con algo que en esencia nunca puede ser representación [algo] que nunca se puede representar inmediatamente" (2009, p. 313). Dicho de manera más transparente, la música es la objetivación misma del más arcano de los misterios: la voluntad. Desconcertantes palabras, sin lugar a dudas, las que aquí se han bosquejado a partir de lo planteado Arthur Schopenhauer; es más, estas se podrían llegar a calificar incluso de extravagantes; pese a esto, en cada una de ellas se halla el fundamento la música; ¿cuál es ese fundamento? Atendamos, brevemente, al modo como Schopenhauer expone estas ideas.

Para el famoso sabio de Fráncfort, como lo denomina Luis Fernando Moreno Claros en su biografía acerca del gran pesimista, resulta evidente que la más "adecuada objetivación de la voluntad [del corazón de las tinieblas] son las ideas (platónicas)" (2009, p. 313). De ahí por qué incentivar el conocimiento de estas por intermedio de "representaciones de cosas individuales", de obras arte (2009, p. 313), sea el objetivo de las artes en general, exceptuando la música; algo elemental, si se tiene en cuenta que todas las artes objetivan la voluntad de forma concreta. Esto se entiende, subraya Schopenhauer, si se ha comprendido plenamente que el mundo no es otra cosa que la múltiple manifestación fenoménica de las ideas "a través del ingreso en el principium individiationis" (2009, p. 313). Por el contrario, la música, en tanto "trasciende las ideas, es totalmente independiente del mundo fenoménico, lo ignora y en cierta medida podría subsistir aunque no existiera el mundo, lo cual no puede decirse de las demás artes" (2009, p. 313). Hay que manifestar que la música no es otra cosa que: "una objetivación e imagen de la voluntad tan inmediata como lo es el mundo mismo. [No] la copia de las ideas, sino la copia de la voluntad misma" (2009, p. 313).

A este respecto, ver lo plantado por Safranski en el libro arriba citado, donde, entre otras cosas, se dice: "en Schopenhauer, (...) el contenido esencial del mundo no es ningún fundamento bueno, sino un abismo, el corazón en las tinieblas" (2010, p. 51). 
Esto explica por qué la música, insiste nuestro autor, genera un efecto más contundente que el de las demás artes; pues mientras estas últimas "hablan de las sombras, [la música habla] del ser" (2009, p. 313), que no es otra cosa que la voluntad o, lo que es exactamente lo mismo, el indómito anhelo de vivir. Por esto, no resulta una casualidad que el autor de El mundo como Voluntady representación termine identificando, en las notas graves, "los grados inferiores de objetivación de la voluntad: la naturaleza inorgánica, la masa del planeta" (2009, p. 314), y, en las notas elevadas, aquellas "nacidas de las vibraciones concomitantes del bajo fundamental" (2009, p. 314), los grados superiores de objetivación de la voluntad.

Si deseamos hacernos una idea clara de este formidable suceso, dice Schopenhauer, basta considerar el surgimiento de todos los cuerpos a partir de la masa del planeta, la cual no puede ser pensable sin la voluntad. De este modo, "el bajo fundamental es a la armonía lo que al mundo, la naturaleza inorgánica, la masa bruta en la que descansa y de la que todo surge y se desarrolla" (2009, p. 314), y los demás intervalos de la escala son identificables con los demás "grados de objetivación de la voluntad" (2009, p. 314). Incluso, a su entender, las disonancias son comparables a los engendros monstruosos de la naturaleza. No extraña, por eso, que para este pensador la voz cantante, la melodía, esté íntimamente ligada a la secreta historia del propio ser humano; al íntimo relato de cada una de sus pulsiones. Así, indica Arthur Schopenhauer: "La música es el lenguaje del sentimiento y la pasión, como las palabras son el lenguaje de la razón” (2009, p. 316).

¿Y qué más podría ser, si la esencia del ser humano radica en que su voluntad aspira a satisfacer aquello que ambiciona, pues, de no ser así, se consumiría en el puro sufrimiento, y, una vez satisfecho, arrojarse de nuevo en brazos del deseo para no verse condenado al más aterrador aburrimiento? Desde el punto de vista de Arthur Schopenhauer esto es, justamente, lo que ocurre también en elámbito de la música; empero, en ella, eso que se ha dado en llamar voluntad y a lo cual, indefectiblemente, se retorna, no es otra cosa más que el bajo fundamental. Pero, ¿a quién le ha sido dado escuchar el palpitante corazón de este bajo fundamental? Para Arthur Schopenhauer la respuesta es evidente: el único capaz de captar, como un pararrayos, las fogosas pulsiones de la voluntad, el "querer y el sentir humanos" y, a partir de ahí, dar a luz la belleza, no puede ser otro que el genio. Con razón el gran Hölderlin escribió en su poema Como cuando en día de fiesta:

Y por eso beben ahora los hijos de la Tierra el fuego celeste sin peligro. 
Pero a nosotros poetas nos corresponde

permanecer descubiertos bajo la tormenta divina,

y tomar con las propias manos

el rayo del padre y entregar al pueblo,

velado en canto, el don divino (2012, p. 401).

No está demás anotar que para Schopenhauer resulta innegable por qué en la música, como en las demás artes, los conceptos se tornan estériles. Así las cosas, habrá que decir entonces que: "el compositor revela la esencia íntima del mundo y expresa la más honda sabiduría en un lenguaje que su razón no comprende" (2009, p. 316). Su música no hace más que hacer patente: “... la alegría, la aflicción, el dolor, el espanto, el júbilo, la diversión y el sosiego mismos... “(2009, p. 317). En último término, "la quintaesencia de la vida" (2009, p. 318), pero sin el sufrimiento. Formulado de otro modo, la música no es otra cosa que la manifestación misma del mundo, el cifrado gemido del guerrero, mas, un gemido como el de Laooconte y sus hijos, que hace patente "todos los impulsos de nuestro ser más íntimo, pero separados de su realidad y [como se ha manifestado] lejos de su tormento". Así, para el autor de El mundo como voluntad y representación, la música "que es una copia de la voluntad misma representa lo metafísico de todo lo físico, la cosa en sí de todo fenómeno. Por lo tanto, podríamos igualmente llamar al mundo música hecha cuerpo o voluntad hecha cuerpo" (2009, p. 319). En síntesis, al decir de Leibniz, según la cita puesta por el propio Arthur Schopenhauer, "la música es el ejercicio oculto de la metafísica por parte de un espíritu que no sabe que está filosofando" (2009, p. 321).

Lo que resuena, así, en La cabalgata de las Valkirias, en esta primera versión impregnada del espíritu de Arthur Schopenhauer, no es más que la "esencia íntima del mundo" en su eterno combate, la tempestuosa pulsión de vivir, el corazón mismo de las tinieblas: la voluntad hecha cuerpo. Según la terminología empleada por Emmanuel Kant, esa “cosa en sî”, fundamento último de toda la realidad y para nada extático, que, cual agitado océano y más allá de toda razón, es el encargado de engendrar el efímero mundo en el que nos ha sido dado habitar. En breves términos, esa impetuosa ansia de vivir que, al materializarse, no tiene más remedio que devorarse a sí misma para poder mantenerse, tan solo un instante más, en la mísera existencia. No cabe duda, en La cabalgata de las valkirias, de Wagner, resuena el eterno combate entre los vivientes; el todo por el todo, la lucha a vida o muerte; en palabras de Goethe: "el espíritu que siempre lo niega" (1968, p. 77). De ahí el famoso grito de batalla que Richard Wagner pone en labios de la portadora 
de la muerte en su reluciente armadura, la valkiria Brünnhilde, y que ha hecho perdurar su nombre ligado a esta música soberbia: “¡Hojotoho! ¡Hojotoho! ¡Heiaha! Heiaha! ¡Hojotoho! ¡Heiaha!” (2007, p. 50).

Este espíritu encarnado por la valkiria Brünnhilde lo captó perfectamente el director estadounidense Francis Ford Coppola en su versión cinematografía de la célebre cabalgata de las valkirias en su conocida película Apocalipse Now. De ahí por qué, luego de buscar lo que resuena en esta música desde una perspectiva metafísica, valga ahora escudriñar en las resonancias de esta en la Era del Crepúsculo de los dioses, en un tiempo signado por el alma del nihilismo. Así, en lo que sigue se hará un examen de esta época a partir de la puesta en escena de la música wagneriana por Coppola, que tomó como punto de partida, como bien se sabe, la cruenta Guerra de Vietnam (1958-1975).

\section{MúsICA Y NIHILISMO ${ }^{7}$}

El lugar: cualquier recóndito paraje del planeta; en este caso, las lejanas tierras de Vietnam. La situación: un escuadrón del ejército norteamericano que se dirige, en varios helicópteros artillados, a una pequeña aldea vietnamita que ha sido elegida como blanco. El estado de ánimo: una mezcla entre miedo y cinismo. De repente, la voz de quien está al mando: "Gran duque 6 águila 7 pon la guerra psicológica bien fuerte. Aquíromeo control. Empieza el baile”. En adelante sólo fuego, destrucción y muerte. Tal es el contexto en el que se deja oír La cabalgata de las valkirias, de Wagner, en la película Apocalipse now. Pero además de efecto psicológico que muestra de manera clara este film y que, como se sabe hoy en día, era utilizado por el ejército norteamericano regularmente en la Guerra de Vietnam, ¿qué es lo que se "esconde" en esta versión de la conocida obra de Richard Wagner que sirve como telón de fondo a una época martirizada por la guerra? ¿Acaso se recurre aquí a esta música como un simple recurso cinematográfico? Y si este no es el caso, ¿qué enmascara esta música en una época, según la célebre sentencia de Dostoievski, "en la que todo vale porque ya nada vale", en la época de "la partida de los dioses"? Vale la pena intentar ahora dar una respuesta a estas preguntas, aunque sepamos, con absoluta certeza, que aquí de lo que se trata es de entablar un "diálogo" con

7 Para abordar la versión de La cabalgata de las valkirias en su versión cinematográfica debida al director Francis Ford Coppola en su conocida película Apocalipse now, es recomendable acudir a esta dirección digital: http://www.youtube.com/ watch?v=tQnLS4IOBHg 
algo que termina desbordando el ámbito mismo de la racionalidad. Pues, como escribió Theodor Adorno en su libro Teoría estética:

... hay algo en la realidad que es reacio al conocimiento racional. Y es que a esta forma de conocer le es extraño el sufrimiento porque cree poderlo subsumir y determinar, cree tener medios para suavizarlo. Lo que apenas puede es expresarlo por propia experiencia: eso sería irracional. El sufrimiento, cuando se convierte en concepto, queda mudo y estéril;..." (1983, p. 33).

Pero, ¿es quizá este sufrimiento del que habla Adorno la otra cara del canto heroico de la valkiria Brünnhilde, lo que se oculta tras esta versión de La cabalgata wagneriana en una época marcada por el espíritu del nihilismo? ¿Es esto, precisamente, lo que resuena en la música de Richard Wagner en una Era, en palabras de Friedrich Nietzsche, habitada por el más inquietante de todos los huéspedes? (1980, p. 32). Sea este el momento de dar respuesta.

La Guerra de Vietnam, para nadie es un misterio, se incrusta en un momento en el que aún humean los yermos campos de batalla de la Segunda Guerra Mundial; dicho en otros términos, a la sombra de un tiempo en el que los seres humanos habían llegado a estados delirantes de autodestrucción. Es más, y puesto que aún continuaban sintiéndose los efectos del estallido de la bomba atómica sobre las ciudades japonesas de Hiroshima y Nagasaki, en aquel instante se tenía la sensación de que hoy, más nunca, la propia especie humana podría estar en riesgo. ¿Era esto, justamente, lo que hizo patente Francis Ford Coppola en una época que había hecho de la música de Wagner su "banda sonora"? Una y otra vez, ¿es justo esto lo que resuena en la música de Richard Wagner en una Era en la que, en palabras de Marx y Engels, "todo lo sólido se desvanece en el aire"? De la respuesta que se dé a estas preguntas dependerá si podremos descifrar o no el carácter que han adquirido los conflictos en el último siglo y, seguramente, aquellos que responderán a las dinámicas de poder de las futuras generaciones.

En lo que sigue se busca, en primera instancia, demostrar que en La cabalgata de las valkirias, en el contexto de la Guerra de Vietnam, en la época del fin de las grandes narrativas, se hace manifiesta de manera radical la voluntad de nada, propia de la época del Crepúsculo de los dioses; en segunda, mostrar las consecuencias de esa perversa moralina de una sociedad altamente represiva; en tercera, señalar que, a pesar de Wagner, su música termina identificándose con un mundo en el que la técnica ocupa un lugar determinante, y finalmente, sostener que 
la música de Richard Wagner se constituye en el preludio de un tiempo signado por el terror. Los dos primeros aspectos serán tratados en el presente apartado, y al tercero y al cuarto se les prestará la suficiente atención en el apartado siguiente, intitulado: La música en tiempos posmetafísicos. No está de más recordar que este último apartado estará acompañado de una inevitable conclusión. Prestemos atención, ahora, a los dos primeros aspectos.

Si algo evidenció el siglo XX es "que ha resultado ser, como Lenin predijo, un siglo de guerras y revoluciones" (2006, p. 9), lo que comprendió perfectamente Hanna Arend y tuvieron que padecer los vietnamitas durante casi dos décadas (no hay que olvidar que en la Guerra de Vietnam se estima que perdieron la vida entre 3.5 y 5.7 millones de vietnamitas, la mayor parte de ellos civiles, y unos 59.000 soldados norteamericanos, muchos de ellos de origen afro o latino). Mejor dicho, un siglo de una violencia sin límites, que terminó, como indica acertadamente a reglón seguido la escritora judía, por convertirse en su "denominador común" (p. 9). Nada sorprendente de un siglo que germinó en medio de los estériles campos que dejó, a su paso, una de las confrontaciones bélicas más mortíferas de la historia humana: la Primera Guerra Mundial.

Expresado de modo más claro, esa época marcada por un profundo sentimiento de ocaso y de soledad que acabó atravesando el alma de poetas, escritores, músicos y otros artistas en aquel preciso momento. Basta recordar aquí destacados nombres como el de Ernst Ludwig Kirchner, Otto Dix, Georg Trakl, Else Lasker-Schüler, Oswald Spengler, Ernst Jünger, Arnold Schönberg e Igor Stravinski. Seres humanos que, de una u otra forma, estuvieron marcados por el espíritu de la escisión y la voluntad de nada tan propio de la época. De esa misma escisión y voluntad de nada, que alcanzó su clímax en los campos de batalla de Verdún, Yprés y Somme, en Hiroshima y Nagasaki, los bombardeos con napalm en las selvas vietnamitas e, incluso, de manera más reciente, en todas las confrontaciones bélicas que se han dado por el dominio del planeta. En otros términos, esa Era signada por un marcado sentimiento de desarraigo y en el que los individuos se sienten habitando una "tierra de nadie".

Pero, ¿qué es lo que llevó a los seres humanos a una situación tan dolorosa, que se hace patente de forma escalofriante en la puesta en escena de La cabalgata de la valkirias según la versión de Francis Ford Coppola? La respuesta parece clara: la tradición occidental, en su conjunto, ha estado modelada por el nihilismo, por una inclinación esencial a la negación de todo lo que existe. De este modo, la famosa 
composición de Richard Wagner, en el contexto dado por el director de cine norteamericano, no sería más que la síntesis o, mejor, la encarnación misma del "espíritu que siempre niega". No podría ser de otra manera, allíse hace manifiesto el más radical instinto de negación, puesto que al ser humano le ha sido arrebatado su ser más propio, y esto no solo porque se muestra allí, en toda su crudeza, su aniquilación, sino porque el ser humano ha perdido aquí su fundamento. En palabras de Heidegger, dichas a propósito de la poesía de Georg Trakl, el hombre ya "no se halla en el viento de lo sagrado" (1990, p. 44), se ha vuelto esencialmente vulnerable. Con razón dice el autor de Ser y tiempo en este mismo texto de forma categórica: "La estirpe desplazada de su modo esencial [ha devenido] por ello una estirpe "aterrada"”, (1990, p. 46).

Hay que decir en este momento que en La cabalgata de las Valkirias, en el contexto de una guerra contemporánea como la de Vietnam, lo que resuena es, ni más ni menos que la voluntad de nada; puesto que allí, como afirma el escritor vasco Castor Narvarte, en su libro Nihilismo y violencia. Ensayos sobre filosofía contemporánea: "La violencia revela una voluntad de nadificación; este es su carácter inmediato: querer reducir algo a nada. (...). Y la voluntad de nadificación nos conduce a un fenómeno registrado en nuestro tiempo bajo el nombre de nihilismo. El nihilismo es, en un sentido más inmediato, vocación a la nada. [De esta manera, dice este autor] la violencia nos pone ante la nada" (2003, p. 30). De ahí por qué La cabalgata de las Valkirias en este contexto no sea más que una vocación hacia la nada, pues en ella la violencia ha tomado la palabra. Así y todo, tal vocación a la nada solo es posible porque, y esto lo comprendió muy bien Sigmund Freud, aún habita un perverso "hombre primitivo" en cada uno de nosotros ${ }^{8}$. Escudriñemos ahora brevemente, a la luz del pensamiento del padre del psicoanálisis, en lo profundo de este "hombre", para comprender mejor qué es lo que resuena en La cabalgata wagneriana en un tiempo en el que instintos más siniestros llevan la voz cantante.

¿Qué mejor ejemplo de esto que aquella época que sirvió a Freud como telón de fondo para sus Consideraciones de actualidad sobre la guerra y la muerte? Efectivamente, en 1915, en medio de una de las confrontaciones más catastróficas de la historia europea, el afamado autor de El Malestar en la cultura da a conocer sus reflexiones a propósito de este nefasto acontecimiento. No podía ser menos, se hacía

8 Resulta bien significativo, en esta dirección, la acusación del presidente ruso Vladimir Putin de que los "rebeldes" sirios han practicado actos de canibalismo. Ver al respecto http://www.eldiario.es/politica/Putin-UE-intervencion-Siria-condenada_0_139636705.html 
necesario en aquel tiempo escudriñar en lo más profundo de la psique humana para comprender cabalmente el origen de ese espíritu autodestructivo que, en aquel preciso momento, se mostraba con toda su virulencia en un lugar de la tierra en el que la gente estaba convencida de pertenecer, no solo a las naciones "más civilizadas" del planeta, sino a aquellas comunidades que habían alcanzado el más alto grado de moralidad.

Para Freud, la respuesta se torna evidente: en lo más insondable de la psique humana habita aún un siniestro personaje capaz de cometer aberrantes y crueles actos de violencia. No resulta por eso extraño que en 1914 los "pueblos [más] civilizados de la tierra" (1988, p. 100) estuvieran empeñados en llevar a cabo el más brutal de los exterminios. Algo que pocos años más tarde, tras la Segunda Guerra Mundial, terminó pareciendo un juego de niños. Un juego por demás, macabro, en el que, dice Sigmund Freud, incluso "el Estado combatiente se permite todas las injusticias y todas las violencias, que deshonrarían al individuo" (1988, p. 101). Nada raro en una época en la que se busca la aniquilación total de aquel que ha sido caracterizado como "enemigo", como tampoco resulta extraño que, en tales circunstancias, el Estado demande de sus ciudadanos no solo una sumisión incondicional, sino el más puro y simple de los sacrificios. Así, reconoce este autor, no resulta insólito por qué, en tales condiciones:

El relajamiento de las relaciones morales entre los pueblos haya repercutido en la moralidad del individuo, pues nuestra conciencia no es el juez incorruptible que los moralistas suponen; es tan sólo, en su origen, "miedo social", y no otra cosa. Allí donde la comunidad se abstiene de todo reproche, cesa también la yugulación de los malos impulsos, y los hombres cometen actos de crueldad, malicia, traición y brutalidad, cuya posibilidad se hubiera creído incompatible con su nivel cultural (1988, p. 101).

Así, en un escenario semejante, los seres humanos son arrojados en un mundo que termina siéndole extraño. Es en este sentido que puede reconocer Freud, en este texto de 1915, que se está en una situación en la que cualquier idea heroica de la guerra, como aquella que tenía en mente Richard Wagner al componer su afamada Cabalgata de las Valkirias, se viene estrepitosamente al piso. Es más, anota el padre del psicoanálisis, en un contexto de una cruenta confrontación bélica, termina cambiándose incluso nuestra óptica acerca de la muerte, pues cualquier ser humano está en condiciones de ser eliminable, y esto con el beneplácito de Estados que se arrogan el derecho de ser guardianes de los principios morales que sustentan toda la civilización. Expresado con más claridad, en tales ambientes de guerra se hace 
patente la tendencia de todo ser humano a la destrucción y el asesinato. Más exactamente, la impostura de una sociedad instituida a partir de la represión y la perversión, y en la que la muerte, aunque parezca extraño, ha acabado trivializándose. En síntesis, recalca Freud, en tales coyunturas se hace manifiesta en nosotros la monstruosidad de ese "hombre primitivo", que ha estado reprimido durante mucho tiempo por la moralina de una sociedad ruin.

Formulado en estos términos, lo que se pronuncia en La cabalgata de las Valkirias, en un tiempo de guerra cruenta, no es otra cosa que la voz de una época que exalta, hasta el mismo delirio, la autodestrucción humana. La voz de ese instinto del ser humano a la perversión, el cual, como se señaló, ha estado largamente reprimido por una sociedad moralista como aquella en la que vivió Richard Wagner, y que hoy el americanismo ha vuelto su estandarte con su arrogante poder técnico-científico. No está de más decir que en una época moldeada por este último, las prácticas destructivas de los seres humanos en contra de otros se han vuelto más despiadadas y violentas. Es justo esto lo que se hace patente en el último de nuestros ejemplos, y cuyo análisis estará acompañado por las reflexiones de un hombre que le correspondió vivir, en carne propia, toda la crudeza de las dos guerras mundiales, que dejaron huella imborrable el siglo XX: Ernst Jünger (1895-1998), cuyo pensamiento nos permitirá escuchar, de forma más nítida, aquello que resuena en la música propia de una era marcada por el desarrollo técnico-científico y el más temible instinto de negación.

\section{LA MÚSICA EN TIEMPOS POSMETAFÍSICOS ${ }^{9}$}

El escenario: un sombrío e indefinido paisaje apocalíptico en el que un ejército de implacables y relucientes máquinas plateadas con forma humana tiene como objetivo la destrucción total de la especie. El año; 2032. El resto: solo oscuridad, relámpagos, fuego y aniquilación. Así, en este desolado paisaje, solo comparable con las delirantes ensoñaciones de Otto Dix, tras la Gran Guerra, incluso las víctimas se reducen a tan solo simples cráneos pulverizados por pesadas máquinas, y frente a aquellos androides exterminadores, un impotente comando de soldados humanos, de una parte, y de otra, un ciborg que encarna los preceptos del americanismo ${ }^{10}$. Todo

$9 \quad$ En lo que concierne a la banda sonora de la película Terminator se sugiere acudir a la siguiente dirección electrónica: http://www.youtube.com/watch?v=-TXFoTUrSYw

10 Conviene anotar aquí que por americanismo no se alude a una simple política de un Estado en concreto, en este caso, los Estados Unidos de América y su "gigantismo", sino, según 
este funesto panorama va alcanzando, en la película Terminator 3, dirigida por Jonathan Mostuw, una intensidad cada vez mayor, a medida que la música electrónica de Brad Fiedel hace manifiesta la destrucción total.

Es claro, ya no resuena aquí La cabalgata de las Valkirias, pero ¿no es esta la música del futuro de la que hablaba Richard Wagner y que ya estaba en ciernes en su obra? ¿Qué es lo que hace evidente está música acerada en una era posmetafísica en la que el desarrollo tecnológico desempeña un papel definitivo? Tal vez la respuesta la tiene un hombre que, como se ha subrayado, en su larga vida tuvo que ser testigo de la incidencia de la técnica en la transformación de todos los conflictos bélicos en los que se vieron involucrados los seres humanos en el siglo XX. Nos referimos, desde luego, al mencionado Ernst Jünger que, desde la década de 1930, intuyó la posibilidad de que los seres humanos se podrían ver abocados a confrontaciones en las que: "Un tipo más duro e inatacable de soldado" (2008, p. 65) ejerciera un rol fundamental. Algo para nada sorprendente, como lo manifestó Jünger desde muy temprano, en un tiempo en que se demostró la formidable capacidad de destrucción del ser humano sirviéndose de la técnica.

De esta suerte, en una época de guerra altamente tecnificada (téngase en mente aquí la guerra de Vietnam o la guerra de las Malvinas y, más recientemente, los conflictos en Afganistán, Irak, Libia, Siria o, incluso, una confrontación imaginaria como la que sirve de telón de fondo a la música para Terminator, en la que una sofisticada tecnología muestra toda su contundencia), lo que se busca es destruir, con una frialdad que hiela las fibras, no solo el cuerpo del "enemigo", sino el medioambiente en el que se mueve. -Estas palabras se entenderán mucho mejor más adelante, cuando aludamos a las consideraciones hechas por Peter Sloterdijk a propósito del origen del atmoterrorismo-. Ahora bien, tal condición solo es explicable si se tiene en cuenta que en la época moderna existe, como se percató atinadamente Ernst Jünger, una estrecha relación entre el "genio de la guerra [y] el espíritu de progreso" (2008, p. 90). Hoy resulta evidente que la realización plena de este funesto vínculo se haya articulado al hecho incuestionable de que, actualmente, el espíritu del americanismo está totalmente compenetrado con alma del desarrollo tecnológico.

la expresión de Martin Heidegger en su texto La época de la imagen del mundo, ese "imperialismo del hombre técnicamente organizado, [en el cual] el subjetivismo del hombre alcanza su cima más alta, desde la que descenderá a instalarse en el llano de la uniformidad organizada. Esta uniformidad [que] pasa a ser el instrumento más seguro para el total dominio técnico de la tierra" (1996, p. 107). 
Desde esta óptica, lo que evidencia la música de Brad Fiedel es, simple y llanamente, esta conjunción nefasta entre el americanismo y el alma del desarrollo tecnológico "en la edad de las masas y las máquinas" (2008, p. 101), según la expresión adoptada por Jünger. Más puntualmente, en la era de grandes aglomeraciones, de armas inteligentes y de drones, lo que resuena en esta música es el metálico sonido de la voluntad de terror. Enunciado de otra manera, aquí lo que se evidencia es la trasmutación del ser humano a un grado sumo de insensibilidad. Así, en la música para Terminator lo que se hace patente es la más feroz voluntad de nihilidad; el hecho incuestionable de que el ser humano, en tales condiciones, queda absolutamente inerme, a merced del brutal poder de la tecnología. No sorprende por eso que Jünger, ya en 1930, haya podido escribir: "Son muchos los sitios donde ya casi se ha desprendido la máscara humanitarista; en su lugar aparece un fetichismo medio grotesco, medio bárbaro de la máquina, un ingenuo culto de la técnica" (2008, p. 120), o que pocos años después de haber sido escritas estas atinadas palabras por parte de Jünger, Walter Benjamin haya podido anotar, en contra de los futuristas $\mathrm{y}$, en particular, del manifiesto de Marinetti, en su famoso texto La obra de arte en la época de su reproductibilidad técnica, lo siguiente:

Este manifiesto -subraya Benjamin- tiene la ventaja de ser claro. Merece que el diálogo adopte su planteamiento de la cuestión. La estética de la guerra actual se le presenta de la manera siguiente: mientras que el orden de la propiedad impide el aprovechamiento natural de las fuerzas productivas, el crecimiento de los medios técnicos, de los ritmos, de las fuentes de energía, urge un aprovechamiento antinatural. (...). La guerra imperialista es un levantamiento de la técnica, que se cobra en el material humano las exigencias a las que la sociedad ha sustraído su material natural. En lugar de canalizar los ríos, dirige la corriente humana al lecho de las trincheras; en lugar de esparcir grano desde sus aeroplanos, esparce bombas incendiarias sobre las ciudades; y la guerra de gases ha encontrado un medio nuevo para acabar con el aura (1973, p. 57).

Una vez llegados a este punto, se hace forzoso cerrar este apartado con algunas reflexiones que nos permitan comprender aquello que se hace ostensible en una época permeada por la voluntad de terror, en la que "la guerra de gases ha encontrado un medio nuevo para acabar con el aura"; es decir, esa misma época que hace manifiesta la música de Brad Fiedel para Terminator. Esta vez tomaremos como punto de partida las cavilaciones de Sloterdijk en su libro Temblores de aire. En las fuentes del terror, del año 2002. Pues si algo caracteriza una época marcada por conflictos altamente 
tecnologizados es el hecho indiscutible de que a través de la tecnología se busca vulnerar, de modo sustancial, el medioambiente de todo aquel que ha sido señalado con el rótulo de "enemigo", tal como considera este filósofo alemán. Piénsese, por ejemplo aquí, no solo en conflictos imaginarios, como el recreado en Terminator, que tiene el nefasto fin de preparar a poblaciones enteras para confrontaciones altamente destructivas (Jünger, 2008), sino, en los conflictos bélicos de los últimos tiempos, cuya característica más relevante es la destrucción y la "reconstrucción", a la manera de aquel niño al que se refiere Heráclito (Nietzsche, 2003).

No cabe la menor duda: en la era de las conflagraciones tecnológicas, "la guerra de gases" (entiéndase por esta la del uso de armas químicas) desempeña un papel preponderante; de ahí por qué, como reconoce Peter Sloterdijk, si existe algo característico de la era presente es lo que este autor denomina atmoterrorismo, cuyo origen se encuentra, a su entender, en el empleo de gas clórico durante la Gran Guerra, a saber, en un tiempo aciago en el que, por primera vez, fue posible llevar a cabo ese infausto vínculo entre nihilismo y terror. No está de más recordar que tal condición trajo amargas consecuencias, y no solo para el ser humano. En aquel momento se introduce el medioambiente en la lucha entre fracciones adversas (Sloterdijk, 2002, p. 43). Dicho de forma más clara, aquí por primera vez el medioambiente se constituye en un arma letal, en tanto que, al respirar, la víctima hace de su propio cuerpo su más feroz enemigo.

A esto se refiere Peter Sloterdijk cuando apunta: "El siglo XX pasará a la memoria histórica como la época cuya idea de la guerra ya no es apuntar al cuerpo del enemigo, sino a su medioambiente. He aquí el pensamiento del terror en un sentido explícito" (2002, p. 45). Esto quiere decir que, con el uso de armas químicas en las confrontaciones bélicas, lo que se busca es vulnerar las condiciones de posibilidad de la existencia misma, puesto que lo más propio del ser humano es "ser-en-lorespirable" Luftung (Sloterdijk, 2002, p. 144). Así que, reconoce el autor alemán, en la Primera Guerra Mundial se da "el paso de la guerra clásica al terrorismo" (2002, p. 46); en síntesis, el paso del asesinato al genocidio. Teniendo en mente una situación semejante es que puede decir Peter Sloterdijk, en su libro: "El terrorismo es la explicación maximalista del otro bajo el punto de vista de su condición de exterminable" (2002, p. 58).

De esta manera, hay que señalar que en la música para Terminator (no resulta por eso fortuito el nombre de este film) lo que se hace patente es el estado de vulnerabilidad al que ha sido arrojado hoy en día el ser humano, y todo gracias el empleo bélico de 
la tecnología, es más, de la biotecnología. Sin embargo, esta música, en modo alguno, denuncia la condición de fragilidad en la que ha caído la humanidad, sino que se funda en la exaltación misma del exterminio, en la más descarada voluntad de aniquilamiento, y, lo que es peor, hace de la muerte un espectáculo. Para terminar, solo resta aquí hacer una pregunta: ante tan triste panorama, ¿qué nos queda? Sea cual sea la respuesta que se dé, no podemos evitar ligar a ella otra pregunta: ¿qué lugar le corresponde ocupar, en tan sombrías circunstancias, a la música? Aesto se va a dedicar, justo, el último apartado de estas reflexiones.

\section{A MANera De CONCLuSIón}

".. la vida sin música constituye simplemente un error, una fatiga, un exilio" (Nietzsche a Peter Gast, 15 de enero de 1888)

Cuán difícil resulta dar una salida a una condición tan lamentable, mucho más cuando se trata de buscarla en el arte, que, para nadie es un secreto, parece hacerse añicos al contacto con la realidad, con esa misma realidad de la que se ha hecho en este lugar una radiografía tan poco alentadora. Con todo, de lo que se trata aquíes de proponer una cura; pero ¿dónde reside esta?, y la música ¿qué papel desempeña aquí? Para un hombre como Arthur Schopenhauer la respuesta a esta cuestión es evidente; la música es, desde luego, la manifestación misma del fundamento del mundo, pero al mismo tiempo lo único capaz de llevarnos a un estado de arrobamiento, a ese ámbito que permite salir, por un instante fugaz, del círculo infernal de dolor y tedio que es en últimas, para este filósofo, la vida. Tal vez teniendo en mente este lúgubre paisaje con el que su maestro representa la existencia humana, Friedrich Nietzsche haya podido escribir a su amigo, el músico Peter Gast, las significativas palabras que sirven de epígrafe a este apartado: "la vida sin música constituye simplemente un error” (citado por Pérez Maseda, 1993, p. 215).

Así, si se acepta lo planteado por Schopenhauer, resulta claro que la salida del laberinto en el que se encuentra el ser humano se debe buscar en la música, pero vista como una especie narcótico que, con su encanto, hace soportable la existencia a los míseros mortales. -Para el famoso filósofo de Danzig es claro que la música de Mozart y Rossini cumple cabalmente esta función-. Desde esta perspectiva, la música no solo sería la objetivación misma del fundamento del mundo, sino una especie de “opio del pueblo", según la conocida expresión de Marx respecto a la religión (1982, p. 491). En síntesis, “desde esta perspectiva [la música] es algo así como tensar un arco, para no caer de la distensión nihilista. [La música] ayuda a vivir, pues de otro 
modo la vida se siente desamparada ante el embate de los sentimientos de absurdo" (Safranski, 2010, p. 22).

¿Y sino existe tal fundamento último del mundo, del cual la música sería su objetivación inmediata, como parece demostrar una época estridente como la nuestra en la que todo ha devenido humo? En tales circunstancias, ¿qué ocurre en el arrobamiento? Quizá el error ha sido, justamente, al modo que lo hizo Arthur Schopenhauer, haber asumido la música desde un enfoque resueltamente metafísico, en tanto que la manifestación misma de la voluntad. Más exactamente, como la expresión de ese anhelo de vivir que para "ser" no tiene otro camino que devorarse a sí mismo: la voluntad de nihilidad. Según el acertado análisis de Nietzsche, hasta el día de hoy, "la música ha sido desposeída de su carácter transfigurador del mundo, de su carácter afirmador, -[resumiendo, hasta el día de hoy, la música ha sido] música de décadence (...) ha dejado de ser la flauta de Dioniso...”(1982, p. 115).

De ahí que, a la manera que lo hace el fogoso autor del Zaratustra, se torne imprescindible "desenmascarar" toda música que haga apología de la muerte, de la voluntad de dominio en nombre del “"'orden moral del mundo"”' (Nietzsche, 1982, p. 117), de la libertad, del pueblo. -iQué ironía, como en tiempos de Nietzsche!, cuando "elemperador alemán [afirmaba] que su "deber cristiano" [era] liberar a los esclavos de África" (1982, p. 120), en un momento en el que, echando mano del social-darwinismo, se estaba consolidando el poder colonial en la cuna misma de la humanidad, hoy el americanismo proclama a los cuatro vientos que su deber "democrático" es salvar la libertad y a buena parte de la humanidad, arrasando, como en tiempos del colonialismo, a pueblos milenarios en los lugares más recónditos de la tierra-. Pero, ¿cuál puede ser esa música que ocupe el lugar de una música permeada por el espíritu del nihilismo, al modo que ocurre en La cabalgata de la Valkirias y la música para Terminator? La respuesta parece obvia: una música que diga sí vida; más exactamente, una música en la que se encarne la voluntad de vida que lleve a sus "espaldas el destino de la humanidad" (Nietzsche, 1982, p. 122); en otras palabras, una música que, sin perder su carácter cosmopolita y multicultural, haga patente el sentido histórico de una comunidad y su relación con la madre tierra, con su propia morada. Con razón aquella misteriosa figura le susurraba al oído en sueños al viejo despreciador de la vida, Sócrates, lo siguiente: "Sócrates, Sócrates cultiva la música” (Platón, 60 e) ${ }^{11}$. Justo estas palabras llegaron un día a

11 Como complemento de lo anterior ver el texto preparatorio al Nacimiento de la tragedia, de Nietzsche, intitulado Sócrates y la tragedia (1984b, p. 213). 
oídos de Eurídice; por eso, cuando vio traspasar a su amado Orfeo las puertas del Hades no dudó en aconsejarlo: "Orfeo, Orfeo, cultiva la voluntad de vida". Hasta aquí ha hablado la Filosofía, ahora le corresponde entonar su canto a la Música.

\section{REFERENCIAS}

Arendt, H. (2006). Sobre la violencia. Traducción Guillermo Solana. Madrid: Alianza.

Fubini, E. (2007). El romanticismo: entre música y filosofía. Traducción M. Josep Cuenca Ordinyana. Valencia: Universidat de Valencia.

Freud, S. (1988). “Consideraciones sobre la guerra y la muerte”. En: El malestar en la cultura. Traducción Luis López Ballesteros y de Torres. Madrid: Alianza.

Goethe, J. W. (1968). Fausto. Traducción J. Roviralta Borrell. Universidad de Puerto Rico, Revista de Occidente. Madrid.

Heidegger, M. (1990). “El Habla en el poema”. En: De camino al habla, traducción Yves Zimmermann. Ediciones del Serbal-Guitard. Barcelona, 1990.

Heidegger, M. (1996). "La época de la imagen del mundo". En: Caminos de Bosque. Traducción Helena Cortés y Arturo Leyte. Madrid: Alianza.

Hölderlin, F. (2012). Poemas. Traducción Eduardo Gil Bera. Barcelona: Lumen.

Jünger, E. (2008). Sobre el dolor. Seguido de Movilización total y Fuego y Movimiento. Traducción Andrés Sánchez Pacual. México D. F.: Tusquets.

Marx, K. (1982). "En torno a la crítica de la filosofía del derecho de Hegel". Introducción. En: Carlos Marx Federico Engels: Obras fundamentales 1. Marx Escritos de juventud. Traducción Wenceslao Roces. México D. F.: FCE.

Moreno Claros, L. F. (2005). Schopenhauer. Vida del filósofo pesimista. Madrid: Algaba Editores.

Narvarte, C. (2003). Nihilismo y violencia. Ensayos sobre filosofía contemporánea, vol. I. San Sebastián. Saturrarán. 
Nietzsche, F. (1982). Ecce homo. Trad. Andrés Sánchez Pascual. Madrid: Alianza.

Nietzsche, F. $\left(1984^{\mathrm{a}}\right) . \quad$ El crepúsculo de los ídolos. TraducciónAndrés Sánchez Pascual. Madrid: Alianza.

Nietzsche, F. (1984b). El nacimiento de la tragedia. Traducción Andrés Sánchez Pascual. Madrid: Alianza.

Nietzsche, F. (2003). La filosofía en la época trágica de los griegos. Trad. Luis Fernando Moreno Claros. Madrid: Valdemar.

Nietzsche, F. (1980). La voluntad de poderío. Traducción AníbalFroufre. Madrid: Edaf.

Nietzsche, F. (1984). L L genealogía de la moral. Traducción Andrés Sánchez Pascual. Madrid: Alianza.

Pérez Maseda, E. (1993). Música como idea, música como destino: WagnerNietzsche. Madrid: Tecnos.

Safranski, R. (2010). Nietzsche. Biografía de su pensamiento. Traducción Raúl Gabás. Barcelona: Tusquets.

Schopenhauer, A. (2009). El mundo como voluntad y representación. Traducción Pilar López de Santa María. Madrid: Trotta.

Sloterdijk, P. (2003). Temblores de aire. En las fuentes del terror. Trad. Germán Cano. Valencia: Pre-textos.

Wagner, R. (2007). La valkiria. Traducción Aitor Laiseca. Madrid: Santillana. 